\title{
PARTICIPAÇÃO E FORMAÇÃO AMBIENTAL EM TEFÉ/AM, NA PERSPECTIVA DA EDUCAÇÃO AMBIENTAL NÃO-FORMAL
}

Eubia Rodrigues ${ }^{1}$

Máximo Billacrês ${ }^{2}$

Resumo: Na Conferência Municipal do Meio Ambiente que ocorreu em Tefé, no primeiro semestre de 2008, identificou-se a ausência dos municípios ao entorno de Tefé. Uma década após essa conferência, quais as informações e formações dos representantes municipais, diante dos contextos ambientais? $\mathrm{O}$ presente artigo visa um esclarecimento à ausência da população em discussões, audiências públicas e manifestações que ocorreram em Tefé nos últimos 10 anos, nos quais foram discutidas questões de interesse coletivo. Nesta perspectiva, Tefé como uma cidade com responsabilidade territorial no Amazonas tem a função de difundir práticas educativas corretas para a melhoria da qualidade de vida dos cidadãos e adjacências, visando a necessidade de desenvolver a Educação Ambiental de caráter não-formal.

Palavras-chave: Tefé; Educação Ambiental; Meio Ambiente.

Abstract: At the Municipal Conference on the Environment, which took place in Tefé, in the first half of 2008, the absence of municipalities around Tefé was identified. A decade after this Conference What is the information and training of municipal representatives, given the environmental contexts? This article aims to clarify the absence of the population in discussions, public hearings and demonstrations that took place in Tefé in the last 10 years, in which issues of collective interest were discussed. In this perspective, Tefé as a city of territorial responsibility in Amazonas has the function of spreading correct educational practices to improve the quality of life of citizens and surroundings, aiming at the need to develop non-formal Environmental Education.

Keywords: Tefé; Environmental Education; Environment.

\footnotetext{
1 Universidade Federal de Rondônia. E-mail: eandrea@uea.edu.br, Link para o Lattes: http://lattes.cnpq.br/3924271025509966

2 Universidade do Estado do Amazonas- UEA. E-mail: billacres@gmail.com. Link para o Lattes: http://lattes.cnpq.br/3032801974162523
} 


\section{Introdução}

$\mathrm{Na}$ Conferência Municipal do Meio Ambiente, que ocorreu em Tefé, no primeiro semestre de 2008, identificou-se a ausência dos municípios ao entorno de Tefé, que na região no médio Solimões, possui o papel de responsabilidade territorial (RODRIGUES, 2011). Uma década após essa conferência, a questão que rodeava esse evento, se apresenta pertinente nos contextos atuais: quais as informações e formações dos representantes municipais, diante dos contextos ambientais?

Nesse contexto, a necessidade de apresentar um quadro de formação ambiental, para a concretização de políticas públicas, se coloca como ferramentas acadêmicas para a sociedade, em tabela com os poderes públicos municipais. Visto que, o ambiente é um objeto social onde interagem dados sociais e elementos naturais dentro de uma construção que tem às vezes a natureza e a cultura (VEYRET, 2007), que em determinados contextos, são (e se tornam) componentes de heranças paisagísticas, que integram na produção e identificação de recursos para diferentes finalidades sociais, desde a conservação de determinados espaços até a produção de mercadorias.

Como as prefeituras atuam dentro da questão ambiental? O que fazer para que a participação coletiva tenha uma presença efetiva? Qual o trabalho das prefeituras junto à sociedade? Será que existe um trabalho integrador, visando um desenvolvimento ecologicamente saudável? Será que as decisões são tomadas coletivamente?

As interrogações acima são pertinentes para a reflexão acerca da participação e formação ambiental da população tefeense. Principalmente quando se discutem problemas de interesses coletivos, problemas estes de ordem socioambiental. O presente artigo visa um esclarecimento à ausência da população em discussões, audiências públicas e manifestações que ocorreram em Tefé nos últimos 10 anos, nos quais foram discutidas questões de interesse coletivo.

Esta carência de público foi verificada nos eventos, principalmente quando ocorreu a elaboração do Plano Diretor do Município, exigência do Ministério das Cidades; nas conferências municipais do meio ambiente; nas audiências públicas referentes ao "apagão" que a cidade sofre todo ano; na audiência pública sobre a escolha do terreno para o aterro sanitário; além de outras manifestações populares, nas quais se faz necessário a participação popular, tendo como consequência o enfraquecimento ou a não realização de projetos que visam à melhoria da qualidade de vida da população e a prevenção de impactos ambientais provocados por projetos desenvolvimentistas.

Este distanciamento relaciona-se à falta de informação ou formação de pessoal para uma participação mais efetiva na gestão ambiental. Portanto, a Educação Ambiental não-formal torna-se essencial para uma transformação ou mudança de postura frente às problemáticas socioambientais. 
Neste artigo procura-se tecer algumas considerações acerca da formação ambiental e a participação efetiva da população em discussões que visem uma melhor qualidade de vida para a sociedade tefeense no contexto amazônico. Primeiramente, é necessário fazer uma revisão na Lei 9.795/99 que dispõe sobre a Educação Ambiental, em seu artigo $2^{\circ}$ que diz que: "A Educação Ambiental é um componente essencial e permanente da educação nacional, devendo estar presente, de forma articulada, em todos os níveis e modalidades do processo educativo, em caráter formal e não-formal" (DIAS, 2003), por isso, o caráter abrangente do processo.

Toda população deve ter no mínimo, formação ou informação correta acerca das questões socioambientais, para posteriormente, ter subsídios para uma discussão mais coerente e apresentar propostas que visem uma melhoria para a coletividade. É verdade que o processo educativo e principalmente a Educação Ambiental deve ser reestruturada para alcançar seus objetivos.

A Constituição dispõe em seus artigos e parágrafos sobre o essencial para a formação do indivíduo, como informação adequada sobre seus direitos e deveres no contexto social, no entanto o que ocorre é o contrário, percebe-se um retrocesso no processo e que os direitos se tornam prioridades para alguns, enquanto outros ficam a mercê das decisões políticas.

É precedente neste artigo, destacar a Educação Ambiental não-formal como subsídio para a participação da população em discussões referentes à questão ambiental. Entende-se por Educação Ambiental não-formal "as ações e práticas educativas voltadas à sensibilização da coletividade sobre as questões ambientais e à sua organização e participação na defesa da qualidade do meio ambiente" (DIAS, 2003). Faz-se necessária uma ação efetiva do poder público, em levar informação verdadeira para a sociedade no que diz respeito à prática ambiental, para uma melhor qualidade de vida.

Em Tefé, estas ações são perceptíveis esporadicamente, ou seja, quando ocorrem os eventos referentes ao Dia Mundial do Meio Ambiente, ao Dia Mundial da Água ou eventos que tenham uma propagação nacional ou internacional, para mostrar que o município está desenvolvendo projetos dentro do contexto, passado o evento, tudo é esquecido.

O que o cidadão tefeense sabe sobre Educação Ambiental está relacionado somente às práticas de limpeza da praia, plantio de árvores, coleta de lixo, além de outras, e não percebe que a Educação Ambiental vai além. Requer uma mudança de postura e fazer o cidadão se ver como parte da natureza, como membro da interação. Ele tem uma visão de mundo construída dentro de uma perspectiva cientificista, e esta gera a separação entre homem natureza.

Percebendo um grande recuo, ao divulgar a Educação Ambiental como um processo que visa à dinâmica social e a construção da coletividade, a prática não formal da Educação Ambiental talvez seja o meio mais viável para atingir a população, não só no contexto tefeense, mas, principalmente, no 
contexto amazônico. O que se tem trabalhado sobre Educação Ambiental em Tefé está relacionado a uma prática prescritiva e reprodutiva, resultando em uma transformação individual dos participantes. Dentro desta perspectiva, os resultados tornam-se insatisfatórios, causando uma impotência nos responsáveis, que almejam realmente uma melhoria de qualidade de vida coletiva. Vale salientar que "se cada um fizer a sua parte", talvez não seja a maneira mais correta de alcançar o objetivo proposto. A Educação Ambiental "deve ser direcionada para a compreensão e busca de superação das causas estruturais dos problemas ambientais por meio da ação coletiva organizada" (QUINTAS, 2000, p.15).

Desta forma, não caberia somente à instituição escola ter toda a responsabilidade pela busca de melhor qualidade de vida de seus pares. Desse modo, a Educação Ambiental não-formal torna-se necessária, pois vai além das paredes das escolas e possibilita que qualquer indivíduo possa se tornar um educador ambiental, basta ter "compromisso com a causa ambiental e com uma educação transformadora e dialógica, devendo esse ser detentor de conhecimentos e habilidades, no campo ambiental e educacional" (QUINTAS, 2000, p.18), ocorrendo em uma gestão participativa.

Isto só acontecerá se houver uma mudança individual de postura (não que não aconteça), mas é um processo lento. Verifica-se esta mudança em pequenos grupos ou comunidades ditas tradicionais, com o apoio de pessoas interessadas ou organizações não governamentais. Em uma sociedade tipicamente urbana, o processo é mais difícil, pois há contraposição dos grandes capitalistas, os quais são os que mais contribuem para o desequilíbrio socioambiental.

\section{Formação e informação para uma Educação Ambiental não formal}

De fato, a problemática destacada é fruto do modo de vida atual que se confronta com o ideal de conscientização coletiva. A consequência de um sistema socioeconômico muito forte caracteriza o homem como um ser individualmente egoísta, tornando uma sociedade desigual onde para muitos, qualquer prática que vise a uma melhoria coletiva pode ser considerada utópica.

Mas, já se percebe alguns pequenos grupos ou comunidades que trabalham e têm um resultado positivo de suas ações frente às questões socioambientais, principalmente comunidades que estão inseridas em áreas de preservação. A intervenção humana, que degrada o meio ambiente, não é resultante de uma prática individual, e sim de uma ação e interação social, resultantes de um modo de produção ou um modelo de desenvolvimento que desvincula o homem da natureza, ou seja, onde a natureza é vista e percebida apenas como fornecedora dos recursos para o crescimento econômico.

Nesta lógica, as práticas jurídicas governamentais, por meio, de criações de leis, que são aplicadas de cima para baixo não compreendem ou não 
reconhecem os espaços locais, desta forma apresentando alternativas que concebem o espaço geográfico e o ambiente de forma homogênea.

A Educação Ambiental não-formal realizada de forma correta, atingindo o público-alvo é a alternativa viável, juntamente com a Educação Ambiental formal, para a transformação socioambiental de um lugar e, posteriormente, atingindo outros lugares.

O lugar como uma parte do espaço onde existe uma interação socioambiental, talvez nos ajude a entender Tefé como um lugar, onde não é percebível uma ação coletiva para a melhoria da qualidade de vida, porque no lugar não há uma ação prática que requeira uma interação da própria população. Isso não acontece por falta de uma Educação Ambiental concreta, através da qual os educadores possam trabalhar crítica e dialogicamente com o objetivo de pensar uma sociedade mais dinâmica e atuante para solucionarmos problemas socioambientais, na qualidade de sujeitos ativos do jogo evolutivo.

Se até o presente momento, a Educação Ambiental esteve mal articulada este é o momento de ação para a construção de processos educativos concretos e com mais rigor, para um resgate de saberes mais produtivos, e isto depende da interação social. Há lugares em que ocorre uma interação conjunta, para um bem comum, então nesses grupos a Educação Ambiental fortalece seu campo teórico-metodológico para se alcançar outros horizontes.

Nesta perspectiva, Tefé como uma cidade de responsabilidade territorial no Amazonas (RODRIGUES, 2011), tem a função de difundir práticas educativas corretas para a melhoria da qualidade de vida dos cidadãos e adjacências. O seu legado histórico só consolida esta posição, pois se tornou ponto de ligação entre as cidades vizinhas e a capital do estado do Amazonas, sobressaindo-se em função da grande circulação de pessoas e mercadorias de diversos lugares do país, ocorrendo um crescimento nas redes de comunicação e transporte, aumentando o número de empresas públicas e privadas, além de novas escolas, a universidade e outras organizações e instituições que se tornam responsáveis para a formulação e execução de programas e atividades vinculados à Educação Ambiental não-formal.

Estando ciente das especulações, contradições e incertezas devido à complexidade e o desafio das questões ambientais, visto a existência de uma racionalidade ambiental (LEFF, 2006) como uma alternativa a racionalidade econômica, a Educação Ambiental tenta se consolidar teórica e experimentalmente. Portanto, a prática não-formal do processo torna mais explícita seus referenciais.

Por que pensar Tefé como o lugar ideal para trabalhar a Educação Ambiental não-formal? Inicialmente, faz-se necessário fazer um comentário sobre os aspectos históricos e geográficos de Tefé e, a partir daí, entender a importância do lugar no contexto geográfico, visto que culturalmente, o lugar é 
resultado das interações e experiências humanas, neste sentido "significa muito mais que o sentido geográfico de localização” (RELPH, 1979, p. 16-17), pois vai além, relaciona-se ao tipo de experiências e envolvimento com 0 mundo, à necessidade de raízes e de segurança. Para contribuir com a conceituação de lugar, Dardel (1952: p. 46) diz que

para o homem, a realidade geográfica é primeiramente o lugar que está, os lugares de sua infância, o ambiente que lhe chama à sua presença. É a terra onde ele passeia, ou ara, a borda de seu vale, ou talvez sua rua ou vizinhança.

Portanto, para desenvolver qualquer atividade e descrever seus problemas, buscando soluções, nada melhor do que quem vivencia ou experiencia o lugar, desta forma o lugar tem um caráter fenomenológico:

Os lugares que conhecemos e gostamos são todos lugares únicos e suas particularidades são determinadas por suas paisagens e espaços individuais e por nosso cuidado e responsabilidade, ou ainda pelo nosso desgosto, por eles. Se conhecemos lugares com afeição profunda e genealógica, ou como pontos de parada numa passagem através do mundo, eles são colocados à parte porque significam algo para nós e são os centros a partir dos quais olhamos, metaforicamente pelo menos, através dos espaços e para as paisagens. E se nos encontramos aprisionados pelas circunstâncias ou ambientes de nossas próprias escolhas, estamos sempre dentro de um lugar que é colorido por nossas intenções e experiências, que também as modificam (RELPH, 1979: p. 18).

Analisando o lugar dentro de uma lógica humanista, percebe-se que a relação homem-natureza é analisada de forma romântica, através da qual os laços de afetividade com o lugar, a partir das relações existentes, são levados em consideração para tal definição. Há ainda que se dizer que o lugar, dentro do método fenomenológico, não compõe somente, uma relação de afetividade, de convivência e felicidade, mas também, a sensação de medo, insegurança, distanciamento, é o que se percebe da população de Tefé, nos últimos dez anos.

Desta forma, o lugar é onde ocorrem as relações humano-naturais, e neste processo, assim como existe afetividade e reconhecimento, pode ocorrer o inverso.

O lugar pode aflorar em escalas diversas. A casa, o bairro são lugares experienciados diretamente, assim como a cidade e a nação, estimadas por uma série de elementos simbólicos, emocionantes, da identidade, do pertencimento ou da propriedade vividos ou projetados no curso da vida ou pela arte, esportes ou educação (TUAN, 1980, p. 91). 
Partindo desta perspectiva percebe-se a existência de um lugar mítico, que pode se tornar concreto ou não. "Sagrado e enraizado, o lugar permanece no íntimo das pessoas ainda que metamorfoseado ou devastado" (TUAN, 1980 , p. 94), tendo como alternativa para ser concretizada, a prática da Educação Ambiental não-formal, de forma abrangente e permanente.

\section{Apresentação do ambiente (lugar) a partir de quem experiência}

Das grandes metrópoles às cidades de pequeno porte, os problemas ambientais são comuns, principalmente em se tratando de países em desenvolvimento, que se tornam palcos de articulações e estratégias políticas, econômicas, sociais e ambientais. Nem São Paulo, uma grande metrópole, nem Tefé uma pequena cidade na selva amazônica, estão fora do processo de Educação Ambiental não-formal que visa sustentabilidade global.

O Amazonas é o estado brasileiro com maior extensão territorial, com área de $1.577 .820 \mathrm{~km}$, dividido em 62 municípios. Entre os mais populosos, no estado do Amazonas, situa-se Tefé, com área aproximada de $148.890 \mathrm{Km}^{2}$ (Figura 1), de acordo com a classificação do IBGE (2010), a cidade faz parte da microrregião número 6 . Distante da capital do Estado a $516 \mathrm{~km}$ em linha reta e $663 \mathrm{~km}$ por via fluvial, localizada entre $31^{\circ} 21^{\prime} 27^{\prime \prime}$ de Latitude Sul e $64^{\circ} 40^{\prime} 21^{\prime \prime}$ de Longitude Oeste (Figura 2). Seus aspectos naturais não diferem muito dos outros municípios que se localizam a montante do médio Solimões rio Amazonas. Apresenta relevo pouco aplainado - altura média de 47 metros acima do nível do mar. Salienta-se que as áreas mais elevadas ficam no interior do município, chegando à cota altimétrica de 100 metros.

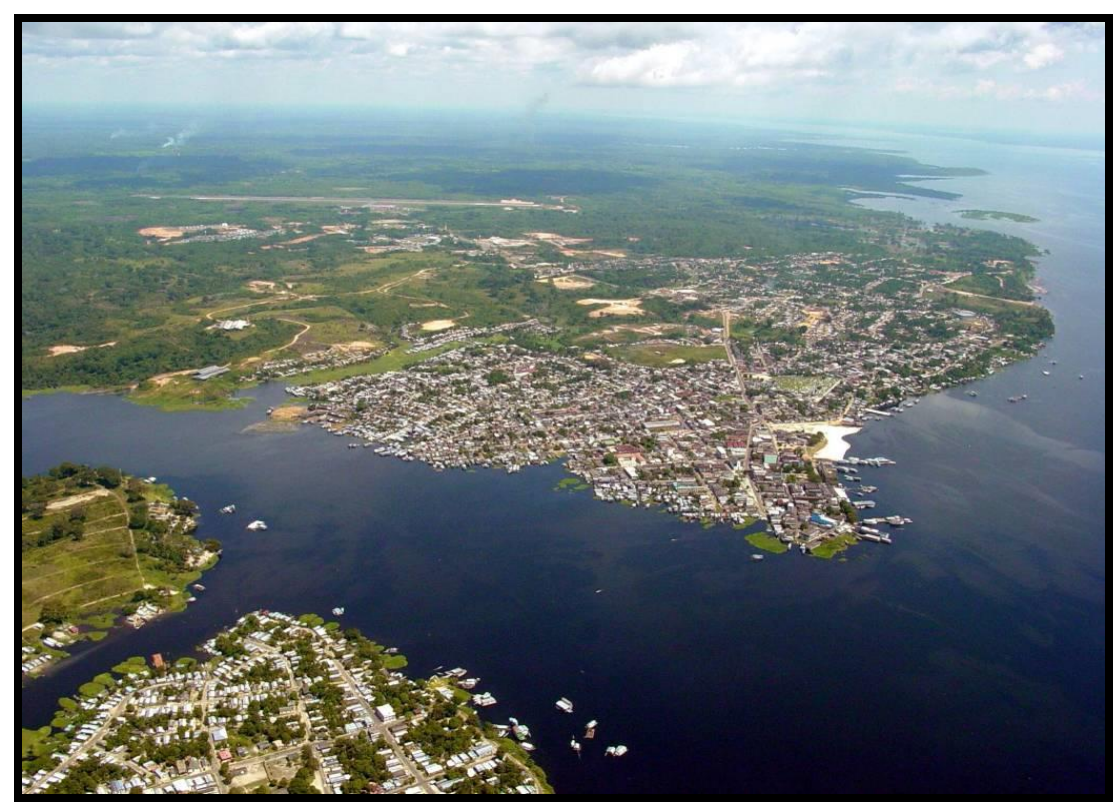

Figura 1: Vista aérea da cidade de Tefé-AM.

Fonte: Joseilton de Souza (2009) 


\section{Localização da Área de Estudo - Município de Tefé, AM}

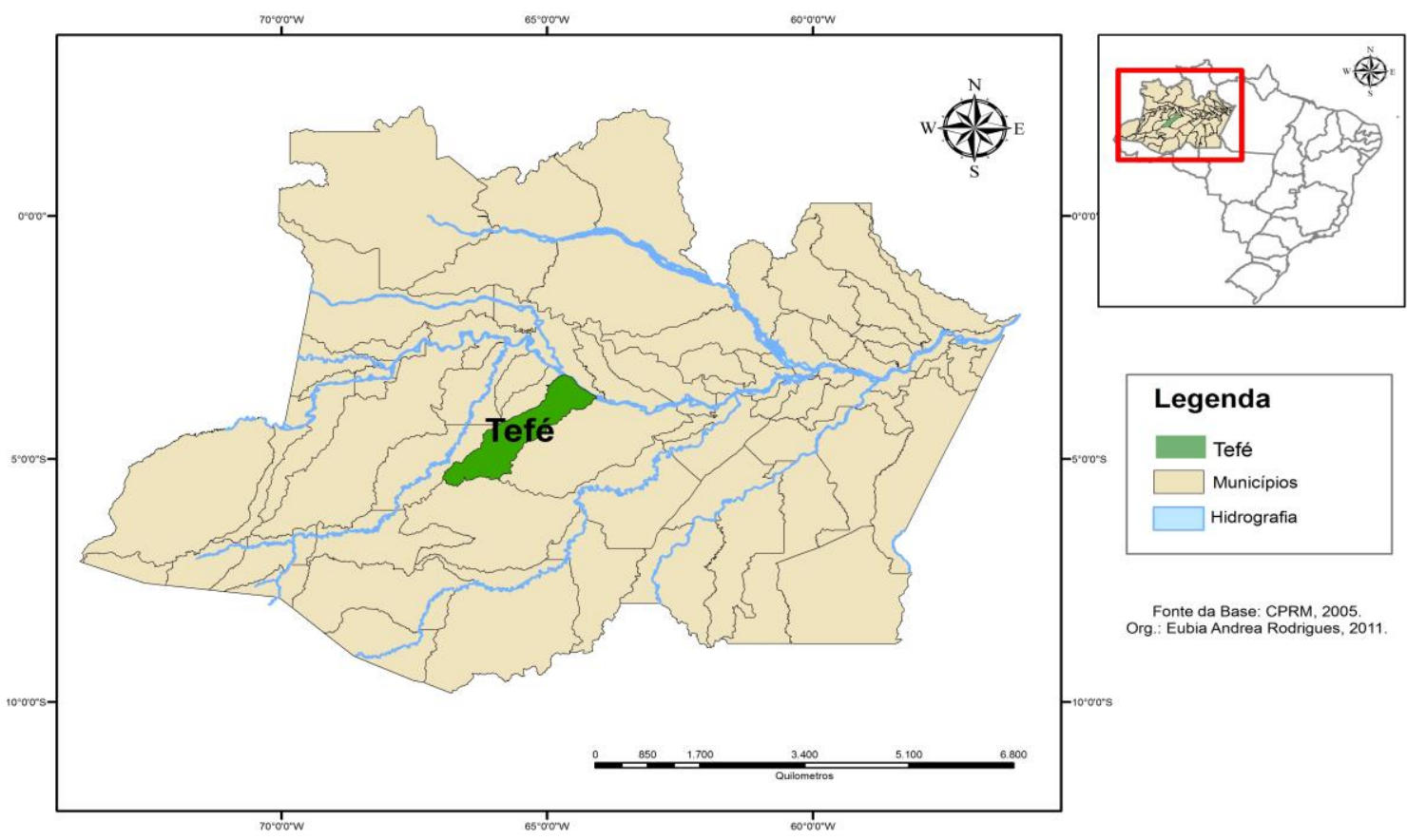

Figura 2: O município de Tefé no contexto do Estado do Amazonas.

Fonte: CPRM (2005) / Org.: Rodrigues (2011)

Sobre as condições naturais de Tefé, o que impressiona seus visitantes é o grande lago que banha a cidade e que tem o nome do município - Tefé proveniente do grande rio que corta grandes extensões do município. Em se tratando da questão ambiental, em torno do paradigma vigente, o município conta com várias áreas de preservação, entre outras: a Floresta Nacional de Tefé, Floresta Ecológica Juami-Japurá, Reserva Extrativista Catuá-Ipixuna, Reserva de Desenvolvimento Sustentável Mamirauá.

Há de se destacar que todas elas contribuem para o desenvolvimento Territorial (DALLABRIDA, 2007). Hoje, Mamirauá é conhecida mundialmente, recebendo turistas de todas as partes do Brasil e do mundo. A questão é: até que ponto o turismo é bom, se a população não tem formação ou informação ambiental necessária para esta prática econômica? Quanto ao aspecto populacional, abriga uma população de 64.576 habitantes aproximadamente (IBGE - Censo, 2010), correspondendo a 2,62\% da população do Estado do Amazonas, com uma densidade de $0,36 \mathrm{hab} . / \mathrm{Km}^{2}$. Segundo os dados oficiais, a média de habitantes por família é de seis pessoas. A origem da população tefeense é resultante do processo de miscigenação entre os portugueses, espanhóis e indígenas.

A migração proveniente de vilarejos do interior, cidades vizinhas e de 
periféricas da cidade trazendo como consequência uma série de problemas socioambientais, como acontece em muitas áreas urbanas do Brasil.

Com base nos dados do Censo de 1980, Tefé tinha uma população de 53.570 habitantes. Em vinte e seis anos, houve um crescimento absoluto da ordem de 64.576 habitantes com o índice de $19.43 \%$, certamente um dos maiores do estado do Amazonas. Entre outros, os motivos que promoveram este crescimento significativo da população tefeense foram à busca de melhores condições de vida, motivadas pelo assentamento da 16 $6^{\text {a }}$ Brigada de Infantaria de Selva; instalações de construtoras provenientes da capital; grande fluxo de garimpeiros e a intensa atividade comercial passando por gêneros alimentícios, material de construção, medicamentos, tecidos, confecções e estivas em geral.

Além do comércio, as atividades primárias são realizadas para a subsistência e um pequeno excedente para o comércio (produção de mandioca e pescado). No setor industrial, que é relativamente pequeno pelo porte do município, destacam-se as serrarias, olarias, frigoríficos entre outros, para o abastecimento do mercado local.

$\mathrm{Na}$ questão social, Tefé apresenta uma grande deficiência, pois a população é pouco assistida na área de saúde, educação e lazer, principalmente na educação, pois mesmo com a implantação da Universidade do Estado do Amazonas, as práticas e projetos ambientais são incipientes.

No que diz respeito ao saneamento básico, este é mais precário ainda, porque as administrações dos últimos trinta anos pouco fizeram para a melhoria das condições estruturais para o setor. Hoje, grande parte do esgoto corre pelas ruas e é todo direcionado para o lago, sem nenhum tratamento, poluindo e contaminando as praias na área urbana.

Outro problema sério diz respeito à política de recolhimento e destinação dos Resíduos Sólidos Urbanos (RSU's). O lixo tornou-se um problema muito grave para a população local, pois o crescimento demográfico é desproporcional à coleta de lixo. A atual administração está procurando reverter a situação, promovendo a limpeza da cidade em lugares alternados, com capinação, poda de árvores, varredura de ruas e logradouros, desobstrução de esgotos, coleta de lixo etc. Mesmo com este esforço concentrado, constata-se que ele ainda é insuficiente, pois a destinação do lixo foge aos parâmetros técnicos recomendados e determinados para este tipo de operação.

Exemplificando este fato, o aeroporto de Tefé permaneceu interditado pela Justiça Federal, por um longo período em 2006, provocando um grande impacto negativo nas condições socioeconômicas da cidade. No que tange às questões ambientais, várias instituições públicas e organizações nãogovernamentais têm desenvolvido trabalhos e ações, procurando conscientizar e sensibilizar, através de campanhas, palestras, seminários etc. Na maioria das 
vezes, fica evidente a pequena participação da população nos projetos e programas desenvolvidos pelas escolas e pela Universidade.

\section{Descrição da situação problema}

A população de Tefé cresceu de forma desordenada e o município não possui infraestrutura e áreas de assentamento adequadas para absorver este grande crescimento populacional em sua área urbana. Este fato obriga, a cada ano, as famílias a se dirigirem para o lago como alternativa de estabelecerem suas residências, contribuindo para 0 aumento significativo de moradias flutuantes, estereotipando a sua urbanodiversidade (TRINDADE JUNIOR, 2013)

O Poder Público Municipal pouco tem feito para a remoção dessas famílias do entorno do lago para a superfície. Estudos feitos mostram que as áreas disponíveis, que serviriam para atenuar e resolver este sério problema pertencem a particulares, às Forças Armadas e à Igreja Católica, dificultando um crescimento horizontal da cidade. Este fato passa a constituir-se numa "mão dupla" - obrigando essas famílias a procurarem o lago como alternativa de moradia, contribuindo, assim, com o processo de degradação ambiental das áreas onde elas se instalam.

Detecta-se nestas áreas, um acúmulo significativo de lixo por parte dos moradores, bem como dos comerciantes fixos nos flutuantes. Muitas vezes, quando não despejam o lixo diretamente no lago, realiza a queima, contrariando as recomendações técnicas, o que provoca sérios problemas de saúde junto à população que fica em contato direto com a fumaça liberada. A prefeitura pouco ou nada tem feito para limpar o manancial.

O problema maior é o alto índice de contaminação das águas, dificultando suas diversas utilizações, tanto para o uso doméstico como para o lazer. No período da vazante do rio, a partir do mês de julho, as praias servem como área de lazer para grande parte da população local e verifica-se uma grande quantidade de material sólido (plásticos, sacolas, garrafas plásticas, vidros) e líquido (óleo despejado pelas embarcações), além dos dejetos fecais provenientes das casas flutuantes, das residências do centro e dos diversos bairros da cidade, o esgoto tefeense é escoado diretamente para o lago. Registra-se, ainda, que grande parte fica em suspensão e é levada pela correnteza até o rio Solimões-Amazonas.

Esses são alguns dos muitos problemas socioambientais que a população tefeense vem enfrentando e que não se percebe reação conjunta em prol da melhoria de qualidade de vida da coletividade. O Lago de Tefé, atualmente, é o único meio de ligação com os municípios vizinhos. Ao Norte: Alvarães, Marãa, Uarini, Fonte Boa, Japurá, Santo Antônio do Içá, Amaturá, Tonantins, São Paulo de Olivença; ao Sul: Coari Codajás, Anori, Anamã Manacapuru, Iranduba e Manaus, a capital do Estado. O Lago serve como área de intercâmbio entre os municípios do Médio e Alto Solimões, ou seja, a 
montante do Rio Solimões-Amazonas, da qual este serve como receptor e fornecedor de mercadorias e uma via de circulação de pessoas.

Desta forma, pode ser analisado dentro de uma abordagem sistêmica, sendo considerado um sistema aberto, pois depende de ambientes externos, recebendo elementos de cunho econômico, social, já que é uma área de intercâmbio de pessoas e mercadorias. A respeito da questão econômica, o município recebe todos os dias barcos grande, pequenos e balsas que transportam constantemente os produtos oriundos de vários lugares do país para abastecer o mercado local, não havendo produção suficiente para abastecimento do mercado interno.

Destaca-se o comércio como a principal atividade econômica, desta forma a variedade de produtos que chegam aos supermercados $e$ mercadinhos, as lojas de confecção e eletrodomésticos são provenientes de outras regiões brasileiras. O que se exporta, predominantemente, é a farinha de mandioca que é produzida de forma rudimentar pelos pequenos agricultores.

No contexto social, Tefé é uma área estratégica do ponto de vista militar, pois foi criada a 16 ${ }^{\text {a }}$ Brigada de Infantaria de Selva, a qual nos últimos treze anos, recebem do sul do país militares com suas famílias, que por vezes permanecem no local quando pedem baixa do Exército, certamente contribuindo para o aumento populacional e difusão de uma nova cultura.

Não só a Brigada, mas também outras instituições colaboram com esse processo de aglomeração urbana. Percebe-se, então, que o espaço urbano com o avanço do capitalismo vem mudando de forma exagerada, transformando e modificando as relações sociais, aumentando as desigualdades sociais que vêm se mostrando de forma assustadora: pessoas que não conseguem comprar ou alugar um lugar decente para morar e são obrigadas a morar, em casebres, favelas, etc., em lugares que não dão a mínima condição de se viver decentemente.

Por estas e outras razões faz-se necessário trabalhar a Educação Ambiental não-formal como uma alternativa em que todas as instituições e empresas pudessem desenvolver um plano operacional que atendesse aos diversos elementos que compõem o cenário de atuação. Uma atuação maior e mais consistente dos grupos envolvidos é o ponto crucial para uma participação mais efetiva da população nos programas e projetos voltados para a resolução das problemáticas socioambientais existentes no município.

Diante de toda a problemática apresentada em decorrência do crescimento urbano, e a análise feita nos últimos dez anos em Tefé, quanto à participação, formação e informação em relação à problemática ambiental, fica explícito que a população está alheia aos acontecimentos e conhecimentos, não ocorrendo esta participação de forma generalizada, mas quando é necessário, o povo se intimida frente às discussões que visam à melhoria da coletividade. 
A preocupação é entender o recuo ou descaso da população para tais discussões, onde esta parece cômoda com às condições impostas pelo sistema, adotando uma posição de subordinação, ou seja, o grupo se ajusta a uma situação de conflito, não ocorrendo transformações internas.

As escolas parecem não contribuir eficazmente para as transformações coletivas positivas. O que se percebe é uma melhoria de vida individual, sem qualidade, e que de forma direta e indireta a população contribui para a manutenção e o enriquecimento de um "pequeno grupo". Os problemas socioambientais que surgem no município parecem não afetar este "pequeno grupo". Desta forma, não há interesse em desenvolver práticas ou programas educativos que visem a uma transformação social positiva.

\section{Considerações finais}

Há a necessidade de desenvolver a Educação Ambiental de caráter nãoformal em Tefé, fazendo com que as instituições públicas e privadas, empresas e outros se mobilizem e procurem definir seu papel dentro da sociedade, e se vejam como um "ingrediente" necessário para a busca de sustentabilidade e melhor qualidade de vida de forma coletiva. Edgar Morin diz que: "Uma sociedade é produzida entre indivíduos e essas interações produzem um todo organizado que retroage sobre os indivíduos para coproduzi-los enquanto indivíduo humano, o que eles não seriam se não dispusessem de instrução, da linguagem e da cultura" (MORIN, 1996, p.182). Morin demonstra que as interações são necessárias para o bem da coletividade, onde as ações ocorrem em decorrência do outro. É necessário o indivíduo perceber que a sociedade é um todo e ele é uma parte, e que a interação das partes leva a uma transformação social, devido à identidade ser, ao mesmo tempo, individual e coletiva (CLAVAL, 1999).

A parceria é necessária ao processo, existindo a integração de informações e ocorrendo uma sensibilização para uma participação coletiva nas ações em prol da solução de problemas através de diversos mecanismos legais de participação comunitária. Analisar a Educação Ambiental como um processo educativo novo é retroceder na busca de conhecimento e informação, é aceitar que os problemas só existiram a partir da Grande Revolução Industrial do século XVIII, é como se anterior a isso, a população vivesse em harmonia com a natureza e não existissem os problemas sociais.

Leff descreve que a crise ambiental é resultante das transformações atuais do mundo real, produzida pelo desconhecimento do conhecimento (LEFF, 2003, p.40). É como se a Educação e seus educadores conseguissem superar qualquer obstáculo que fosse responsável pela desestrutura do modo de vida dos grupos. "A crise ambiental é o resultado do desconhecimento da lei (entropia), que desencadeou no imaginário economicista uma 'mania de crescimento', de uma produção sem limites" (LEFF, 2003, p.21). 
No entanto, não se pode negar que a Educação Ambiental esteve adormecida, esteve presa ao modelo socioeconômico vigente. E hoje, ressurge com determinações voltadas "para um processo educativo focado no indivíduo e na transformação de seu comportamento" (LOUREIRO, LAYRARQUES E CASTRO, 2006, p.26). E a Educação Ambiental, por ser abrangente, tem o caráter não-formal, que contribui eficazmente na formação inicial e continuada dos educadores e educandos em uma perspectiva crítica capaz de construir a sustentabilidade socioambiental participativa. "É um processo integrado e amplo cujo objetivo é a capacitação dos indivíduos para a ampla compreensão das diferentes repercussões ambientais das atividades humanas, tornando-os aptos a agir ativamente em defesa da qualidade ambiental' (ANTUNES, 1999, P. 79). A Educação Ambiental não-formal tem caráter interdisciplinar e tem um papel relevante em Tefé, uma vez que os problemas ambientais causados pela sociedade devem ser solucionados com a participação de todos e com o apoio público e privado, baseado no respeito aos direitos humanos e à diversidade cultural.

A interação, muito discutida, é a resposta para os problemas, seja de qualquer ordem, considerando que o indivíduo não sobreviva sozinho. Diaz (1995, p. 33) diz que:

[...] não se pode esquecer que os valores e as atitudes sempre são adquiridos em contextos de realidades e interação da pessoa com seu ambiente, como projetos ideais de comportarse e de existir que o indivíduo aprecia e busca ao mesmo tempo, orientando sua atividade. Daí a importância da relação dinâmica com os problemas da realidade; o problema ambiental é um dos mais significativos e socialmente preocupantes, junto com outros muito ligados a ele: o consumo, o subdesenvolvimento ou a desigualdade.

A busca de um desenvolvimento tem que ser estabelecida por lei, tem que ser cumprido e cobrado pelo indivíduo. Necessita-se então, de uma formação de consciência socioambiental abrangente para que se possa acreditar em uma mudança ética e para que haja ações responsáveis para uma transformação individual, local e global. As leis ambientais brasileiras são bem elaboradas, mas nem sempre são cumpridas, pois o que vale é o poder do capital.

\section{Referências}

ANTUNES, P.B. Educação Ambiental. - Rev. Direito. -V3- n6 - Rio de Janeiro, 1999.

CLAVAL, P. A Geografia Cultural. Editora: UFSC, 1999. 
DALLABRIDA, V. R. A Gestão Social dos Territórios nos Processos de Desenvolvimento Territorial: Uma Aproximação Conceitual. Sociedade, Contabilidade e Gestão (UFRJ), v. 2, p. 44-60, 2007.

DARDEL, E. L'Homme et la terre: Nature de la Réalité Geographique. Presses Universitaires de France. Paris, 1952

DIAS, G.F. Educação Ambiental: princípios e práticas. 8ª Ed. São Paulo: Gaia, 2003.

DIAZ, A.P. La educación ambiental como proyecto. ICE Universitat Barcelona- Editorial Horsori, 1995.

IBGE - Instituto Brasileiro de Geografia e Estatística. - Censo 2010.

LEFF, E. A complexidade ambiental. Tradução Eliete Wolff. - São Paulo: Cortez, 2003.

LEFF, E. Racionalidade ambiental: a reapropriação social da natureza. Rio de Janeiro: Civilização Brasileira, 2006.

LOUREIRO, C.F.B; LAYRARGUES, P.P.; CASTRO, R.S. (orgs.). Pensamento complexo, dialética e Educação Ambiental. São Paulo: Cortez, 2006.

MELO, J.B. Descortinando e (re) pensando categorias espaciais com base na obra de YI-Fu-Tuan. In: ROSENDHAL, Z. CORREA, R. L. Matrizes da Geografia Cultural. Rio de Janeiro: EdUERJ, 2001.

MORIN, E. Ciência com consciência. Rio de Janeiro: Bertrand Brasil, 1996.

QUINTAS, J.S. Pensando e Praticando a Educação Ambiental na Gestão do Meio Ambiente. IBAMA- Brasília, 2000.

RELPH, E.C. As bases fenomenológicas da Geografia. 1979.

RODRIGUES, E. A. Rede urbana do Amazonas: Tefé como cidade média de responsabilidade territorial na calha do médio Solimões. (Dissertação Mestrado em Geografia). Universidade Federal do Amazonas, 2011.

SEPLAM - Secretaria de Estado de Planejamento e Desenvolvimento Econômico - Perfil Municipal - Tefé.

TRINDADE JR., S-C. C. Das "cidades na floresta" às "cidades da floresta": espaço, ambiente e urbanodiversidade na Amazônia brasileira. Papers do NAEA (UFPA), v. 321, p. 1-22, 2013.

TUAN, Y. Topofilia: um estudo da percepção, atitudes e valores do meio ambiente. São Paulo: Difel, 1980.

VEYRET, Y. Dictionnaire de I'Environnement. Armand Colin, Paris, 2007. 